\title{
Study on the Influential Factors of Carbon Emissions from Thermal Power Industrial in China Using Partial Least Square Regressive Model
}

\author{
Mei Liu ${ }^{a}$, Jing-Yan Li ${ }^{b}$ \\ School of North China Electric Power University BaoDing, Hebei 071000, China \\ aliumei_w@163.com, b15932022562@163.com
}

Keywords: carbon emissions, thermal power, the Partial Least Square Regressive model, influential factors.

\begin{abstract}
This paper firstly analyzed the current thermal power situation in China, and then determined several influential factors by referring to the Kaya identity. Finally, the Partial Least Square Regressive model is applied on this issue. To validate the model, this paper calculated the actual Carbon emissions from thermal power industrial by means of the formula formulating by the Intergovernmental Panel on Climate Change’s 2006 guide from 1991-2014 across China. Under the model, we find that the amount of population, consumption of the coal and the ritio of the thermal power are the main factors influencing the carbon emissions from thermal power industrial.
\end{abstract}

\section{Introduction}

Due to the rapid grow of the economy of China, the consumption of primary energy and the emission of greenhouse gases has increased rapidly, meanwhile China has become the most greenhouse gases emission country in 2007. With the development of China's industrialization and urbanization, the scale of thermal power is becoming larger and larger. The installed capacity of China has up to 1.36 billion kilowatts by the end of 2014, which is ten times of the 0.138 billion kilowatts in 1990s, improving by $10 \%$ average annual growth. Among it, the installed capacity of non-fossil energy has up to 0.45 billion kilowatts, with the proportion surpassing 25 percent at the first time [1]. Therefore, to investigate how to control the carbon emissions basing the unceasing development of thermal power situation makes sense.

At present, related scholars have done a serious of researches centering on the calculation and prediction of carbon emissions. Bo-Qiang Lin adopted LMDI and STIRPA models to analyze the main factors of carbon emission per capita of China [2]. Xiao-Yan Shen adopted Grey model to predict the carbon emissions and conclude that we must adjust the energy consumption structure if the population policy will not change [3]. Chang-Kai Wang also adopted LMDI model to investigate the influential factors of electricity industrial, which found that the economy scale is the most important factor [4].

But by far, there has rarely paper to investigate the carbon emission from the thermal power industrial using the Partial Least Square Regressive model, so this paper plays a very significant role in controlling the carbon emission in China.

\section{Establishment of the model}

\section{Selection and analysis of the indicators.}

Kaya identity is created by Kaya Yoic, a Japanese scholar, and is widely used to calculate carbon emission and analyze the influential factors [5-7]. The model and its specific definitions of all variables are expressed as follows:

$$
\mathrm{C}=\frac{\mathrm{C}}{E} \cdot \frac{E}{G D P} \cdot \frac{G D P}{P} \cdot P
$$

Where $C$ represents the carbon emission, E represents the consumption of energy, GDP is the abbreviation of Gross Domestic Product, and P represents the amount of population. Based on this, 
and combing the characteristic of the thermal power industrial, this paper will select indicators from the generation, distribution, and usage of the power three aspects. Thus, this paper selected the ritio of thermal power, the consumption of the coal, the distribution loss of the power, the population and the GDP as the investigated indicators.

\section{Introduction of the model.}

In view of the issue that the variables we studied may have multiple linear correlation, this paper decide to adopt the Partial Least Square Regressive model to solve the problem.

The Partial Least Square Regressive method integrate principle component analysis, canonical correlation analysis and linear-regression analysis which can acquire the maximum to improve the precision of correlation analysis of the model [8]. The specific model process is as follows:

Firstly, we should acquire the observation sample of independent variables $\left\{\mathrm{x}_{1}, \mathrm{x}_{2}, \ldots, \mathrm{x}_{\mathrm{p}}\right\}$ and dependent variables $\left\{\mathrm{y}_{1}, \mathrm{y}_{2}, \ldots, \mathrm{y}_{\mathrm{q}}\right\}$ and then get the data table $\mathbf{X}=\left[\mathrm{x}_{1}, \mathrm{x}_{2}, \ldots, \mathrm{x}_{\mathrm{p}}\right], \mathbf{Y}=\left[\mathrm{y}_{1}, \mathrm{y}_{2}, \ldots, \mathrm{y}_{\mathrm{q}}\right]$. The main line of this model is: Respectively extract the ingredients $\mathbf{t}_{\mathbf{1}}$ and $\mathbf{u}_{\mathbf{1}}$, where $\mathbf{t}_{\mathbf{1}}$ is the linear combination of the independent variables $\mathbf{x}_{1}, \ldots, \mathbf{x}_{\mathbf{p}}$, and $\mathbf{u}_{\mathbf{1}}$ is the linear combination of the dependent variables $\mathbf{y}_{\mathbf{1}}, \ldots, \mathbf{y}_{\mathbf{q}}$. In addition, $\mathbf{t}_{\mathbf{1}}$ and $\mathbf{u}_{\mathbf{1}}$ need to be satisfied that they should carry the most variability information and be up to the maximum correlation. The specific steps of algorithm are as follows:

(1) Standardizing the data of $\mathbf{X}, \mathbf{Y}$ and respectively obtaining the standard array $\mathbf{E}_{\mathbf{0}}$ and $\mathbf{F}_{\mathbf{0}}$.

(2) Calculating the regularization eigenvector $\boldsymbol{w}_{\mathbf{1}}$ corresponding to the maximum eigenvalue of matrix $\mathbf{E}_{\mathbf{0}}{ }^{\mathbf{T}} \mathbf{F}_{\mathbf{0}} \mathbf{F}_{\mathbf{0}}{ }^{\mathbf{T}} \mathbf{E}_{\mathbf{0}}$, and acquiring the first component $\mathbf{t}_{\mathbf{1}}=\mathbf{E}_{\mathbf{0}} \mathbf{w}_{\mathbf{1}}$.

(3) Calculating respectively the regression equation $\mathrm{E}_{0}=\mathrm{t}_{1} \mathrm{p}_{1 \mathrm{~T}}+\mathrm{E}_{1}$ and $\mathrm{F}_{0}=\mathrm{t}_{1} \mathrm{r}_{1 \mathrm{~T}}+\mathrm{F}_{1}$, thereinto $\mathbf{E}_{1}$ and $\mathbf{F}_{\mathbf{1}}$ is the residual matrix of $\mathbf{E}_{\mathbf{0}}$ and $\mathbf{F}_{\mathbf{0}}$, and $\mathbf{p}_{\mathbf{1}}$ and $\mathbf{r}_{\mathbf{1}}$ can expressed as the follows:

$$
\begin{aligned}
& p_{1}=\frac{\mathbf{E}_{0}^{T} t_{1}}{\left\|t_{1}\right\|^{2}} \\
& r_{1}=\frac{\mathbf{F}_{0}^{T} t_{1}}{\left\|t_{1}\right\|^{2}}
\end{aligned}
$$

(4) Testing the convergence. In this section, cross validation test should be applied to validate the precision: if it dissatisfies the equation $\mathbf{E}_{\mathbf{0}}=\mathbf{E}_{\mathbf{1}}, \mathbf{F}_{\mathbf{0}}=\mathbf{F}_{\mathbf{1}}$, it should repeat the above steps up to it meets the requirements. Finally, we can get the following equation:

$$
F_{0}=t_{1} r_{1}^{T}+t_{2} r_{2}^{T}+\cdots+t_{h} r_{h}^{T}
$$

(5) Establishing the regression model of $\mathbf{E}_{\mathbf{0}}$ and $\mathbf{F}_{\mathbf{0}}$, we can get $\mathbf{F}_{\mathbf{0}}=\mathbf{E}_{\mathbf{0}} \mathbf{B}+\mathbf{F}_{\mathbf{A}}$.

$$
\mathbf{B}=\sum_{j=1}^{h}\left[\prod_{i=1}^{j-1}\left(\mathbf{I}-w_{i} p_{i}^{T}\right) w_{j}\right] r_{j}^{T}
$$

Where $\mathbf{I}$ is unit matrix and $\mathbf{F}_{\mathbf{A}}$ is residual matrix.

(6) Establishing the original regression equation of independent variable $\mathbf{X}$ and dependent variable $\mathbf{Y}$ by de-normalizing $\mathbf{E}_{\mathbf{0}}$ and $\mathbf{F}_{\mathbf{0}}$, we can get the following equation:

$$
\mathbf{Y}=\mathbf{X B}_{g}+\mathbf{C}
$$

Where

$$
\begin{gathered}
\mathbf{B}_{g}=\mathbf{D}_{x}^{-1} \mathbf{B D}_{y} \\
\mathbf{C}=m_{y}-m_{x} \mathbf{B}_{g}
\end{gathered}
$$

In the above equation, $\mathbf{D}_{\mathbf{x}}$ and $\mathbf{D}_{\mathbf{y}}$ respectively represent the diagonal matrix consisting the variance of the list of $\mathbf{X}$ and $\mathbf{Y}$, and $\boldsymbol{m}_{\boldsymbol{x}}$ and $\boldsymbol{m}_{\boldsymbol{y}}$ respectively represent the column vector consisting the lists of $\mathbf{X}$ and $\mathbf{Y}$. 


\section{Model for evaluating carbon emissions of the thermal power industrial}

\section{The original data.}

The original data are shown as the Tab. 1.

Tab. 1 Index data

\begin{tabular}{cccccc}
\hline year & $\begin{array}{c}\text { the ritio of } \\
\text { thermal } \\
\text { power/\% }\end{array}$ & $\begin{array}{c}\text { the consumption of } \\
\text { the coal/ hundred } \\
\text { million tons }\end{array}$ & $\begin{array}{c}\text { the distribution loss } \\
\text { of the power/billoin } \\
\text { kilowatt hour }\end{array}$ & $\begin{array}{c}\text { Population/ } \\
\text { hundred } \\
\text { million people }\end{array}$ & $\begin{array}{c}\text { GDP } \\
\text { / hundred } \\
\text { billion yuan }\end{array}$ \\
\hline 1991 & 81.53789388 & 3.01191 & 48.75 & 11.5823 & 22.0056 \\
1992 & 82.42963631 & 3.34594 & 54.6 & 11.7171 & 27.1945 \\
1993 & 81.58327965 & 3.68317 & 61.91 & 11.8517 & 35.6732 \\
1994 & 80.37238169 & 4.005311 & 59.61 & 11.985 & 48.6375 \\
1995 & 79.81502982 & 4.444015 & 74.45 & 12.1121 & 61.3399 \\
1996 & 81.26793948 & 4.880859 & 76.95 & 12.2389 & 71.8136 \\
1997 & 81.45389477 & 4.89792 & 79.84 & 12.3629 & 79.715 \\
1998 & 80.95523924 & 4.948926 & 79.09 & 12.481 & 85.1955 \\
1999 & 82.34809973 & 5.116352 & 86.19 & 12.5909 & 90.5644 \\
2000 & 82.19164945 & 5.58112 & 93.67 & 12.6743 & 100.2801 \\
2001 & 79.91828741 & 5.979786 & 103.35 & 12.7627 & 110.8631 \\
2002 & 80.90326481 & 6.860003 & 116.87 & 12.8453 & 121.7174 \\
2003 & 82.71624324 & 8.196584 & 126.07 & 12.9227 & 137.422 \\
2004 & 81.49511417 & 9.196156 & 142.06 & 12.9988 & 161.8402 \\
2005 & 81.88508395 & 10.366294 & 170.65 & 13.0756 & 187.3189 \\
2006 & 82.68748277 & 11.876391 & 185.88 & 13.1448 & 219.4385 \\
2007 & 82.97694687 & 12.791725 & 206.17 & 13.2129 & 270.2323 \\
2008 & 80.47812442 & 13.265237 & 213.79 & 13.2802 & 319.5155 \\
2009 & 80.29774003 & 14.396729 & 225.82 & 13.345 & 349.0814 \\
2010 & 79.19665523 & 15.374248 & 256.82 & 13.4091 & 413.0303 \\
2011 & 81.34274839 & 17.557853 & 270.07 & 13.4735 & 489.3006 \\
2012 & 78.05054586 & 18.353099 & 289.62 & 13.5404 & 540.3674 \\
2013 & 78.1901967 & 19.517738 & 314.07 & 13.6072 & 595.2444 \\
2014 & 75.55694406 & 18.45253 & 309.99 & 13.6782 & 643.974 \\
\hline
\end{tabular}

\section{Empirical studying.}

This paper investigates the carbon emissions of thermal power industrial based on the five factors mentioned above, that is the ratio of thermal power, the consumption of the coal, the distribution loss of the power, the amount of population, and GDP. They are respectively expressed as $x_{1}, x_{2}, x_{3}, x_{4}$, and $x_{5}$.

Using the Partial Least Square Regressive method mentioned above, we find that the first two gradients can account for 97.55 percent for the independent variable; thus, we only choose two ingredients. After implementing the steps mentioned above, the final regression equation can be expressed as follows:

$$
\mathrm{y}=-1596.856+4.627 \mathrm{x}_{1}+14.853 x_{2}+0.888 x_{3}+107.28 x_{4}+0.357 x_{5}
$$

Using the model to calculate the carbon emission of the thermal power industrial, the results are shown as Tab. 2.

\section{Model testing.}

To validate the model, this paper collected some data about the amount of coal, petroleum, and natural gas by using the formula of carbon emissions formulating by the Intergovernmental Panel on Climate Change’s 2006 guide from 1991-2014 across China. [9-11] The formula is as follows:

$$
E=\sum_{\mathrm{i}=1}^{3} E C_{i} \times E F_{i} \times \mathrm{f}_{i}
$$

Where $\mathrm{E}$ represents the production of carbon emissions, $\mathrm{EC}_{\mathrm{i}}$ represents the consumption of the $i$ th energy, $E F_{i}$ represents the coefficient of carbon emissions of different kinds of energy, $f_{i}$ represents the value of the standard coal coefficient of different kinds of energy. In this paper, $\mathrm{EF}_{\text {coal }}=0.7266$, 
$\mathrm{EF}_{\text {petroleum }}=0.5588, \mathrm{EF}_{\text {natural gas }}=0.4234$, and $\mathrm{f}_{\text {coal }}=0.7143 \mathrm{~kg}$ standard coal $/ \mathrm{kg}, \mathrm{f}_{\text {petroleum }}=1.4286 \mathrm{~kg}$ standard coal $/ \mathrm{kg}, \mathrm{f}_{\text {natural gas }}=1.33 \mathrm{~kg}$ standard coal $/ \mathrm{kg}$. The original data and the results are shown as Tab. 3:

Tab. 2 The prediction values of carbon emissions

\begin{tabular}{lc}
\hline year & The predicted values of carbon emissions/million tons \\
\hline 1991 & 118.810730586702 \\
1992 & 149.402467319142 \\
1993 & 174.447677861852 \\
1994 & 190.512676121787 \\
1995 & 225.787677740382 \\
1996 & 258.556097798407 \\
1997 & 278.355931260834 \\
1998 & 290.765132202339 \\
1999 & 319.703314003876 \\
2000 & 344.934217554887 \\
2001 & 362.187237345474 \\
2002 & 404.551267481748 \\
2003 & 454.862240149525 \\
2004 & 495.124591231617 \\
2005 & 557.011640548425 \\
2006 & 615.551197195959 \\
2007 & 673.917196737078 \\
2008 & 700.949564420969 \\
2009 & 745.095457473019 \\
2010 & 811.720268186729 \\
2011 & 899.954845194162 \\
2012 & 939.277343971175 \\
2013 & 1005.6623447536 \\
2014 & 999.032937460309 \\
\hline
\end{tabular}

Tab. 3 The original data and the results

\begin{tabular}{ccccc}
\hline year & $\begin{array}{c}\text { Coal/ten } \\
\text { thousand tons }\end{array}$ & $\begin{array}{c}\text { Petroleum/ ten } \\
\text { thousand tons }\end{array}$ & $\begin{array}{c}\text { Natural gas/ hundred } \\
\text { million cubic meters }\end{array}$ & $\begin{array}{c}\text { Actual carbon } \\
\text { emissions/million tons }\end{array}$ \\
\hline 1991 & 30119.1 & 1270.5 & 6.4 & 166.8240763 \\
1992 & 33459.4 & 1299.7 & 6.5 & 184.3993153 \\
1993 & 36831.7 & 1601.16 & 8.23 & 204.4058827 \\
1994 & 40053.11 & 1178.4 & 8.31 & 217.7549398 \\
1995 & 44440.15 & 1358.46 & 7.9 & 241.9384668 \\
1996 & 48808.59 & 1238.58 & 7.45 & 263.6287793 \\
1997 & 48979.2 & 1662.11 & 21.28 & 268.6741077 \\
1998 & 49489.26 & 1304.76 & 16.05 & 268.1741282 \\
1999 & 51163.52 & 1228.56 & 12.68 & 276.0656334 \\
2000 & 55811.2 & 1178.15 & 15.21 & 299.927621 \\
2001 & 59797.86 & 1213.55 & 13 & 320.7769491 \\
2002 & 68600.03 & 1275.57 & 11.05 & 366.8464229 \\
2003 & 81965.84 & 1394.4 & 13.24 & 437.2883098 \\
2004 & 91961.56 & 1653.49 & 19.03 & 491.5615016 \\
2005 & 103662.94 & 1306.42 & 30.12 & 550.1467151 \\
2006 & 118763.91 & 931.25 & 57.56 & 627.0725352 \\
2007 & 127917.25 & 718.55 & 80.68 & 674.1832703 \\
2008 & 132652.37 & 504.08 & 81.97 & 697.1195598 \\
2009 & 143967.29 & 393.17 & 134.24 & 757.9032113 \\
2010 & 153742.48 & 385.33 & 161.78 & 810.1257132 \\
2011 & 175578.53 & 319.76 & 197.83 & 924.9636877 \\
2012 & 183530.99 & 292.39 & 204.41 & 966.3898197 \\
2013 & 195177.38 & 265.08 & 218.65 & 1027.419662 \\
2014 & 184525.3 & 254.09 & 228.19 & 972.5837464 \\
\hline$*$ The data are all derived from China Energy Statistical Yearbook (physical quantity)
\end{tabular}

*The data are all derived from China Energy Statistical Yearbook (physical quantity) 
After calculation, we get the average relative residual (relative residual equals to the predicted carbon emissions subtracts out actual carbon emissions and then divided by the predicted value) of the actual values and predicted values, which reads 0.0709187 . That means the model imitation has a good result. The algorithm of average relative residual is that: firstly, using the predicted values subtract out the actual values and then dividing by the actual values, finally averaging these numbers.

By observing the regression equation, we can easily find that the population, consumption of coal and the proportion of the thermal power are the main factors influencing the carbon emissions from thermal power industrial.

\section{Conclusions}

This paper firstly analyzed the current thermal power situation in China, and then determined several influential factors by referring the Kaya identity. Finally, the Partial Least Square Regressive model was applied on this issue. To validate the model, this paper calculated the actual Carbon emissions from thermal power industrial by means of the formula formulating by the Intergovernmental Panel on Climate Change’s 2006 guide from 1991-2014 across China. Through calculation, the average relative residual is 0.0709187 . Under the model, we find that the population, consumption of coal and the proportion of the thermal power are the main factors influencing the carbon emissions from thermal power industrial.

In addition, the structure of China's electric power is mainly the thermal power and the energy structure "rich coal, lack oil and miss gap" determined the thermal power industrial mainly used coal. This phenomenon results in China becoming the biggest carbon emission country in the world. To reduce the carbon emission, China should go on optimizing the power structure.

Based on the results of the model, and with the implement of two-children policy in China, the population will continue to increase and the demand for power will increasingly crease. Thus, how to contain the emission of carbon emission is becoming a critical problem for China. For the moment, optimizing energy structure in the thermal power industrial and advocating wind power generation and solar power generation are effective ways.

\section{References}

[1] China Electricity Council, Present situation and expectation of China's electricity industrial(2014)[R/OL], Information on http://www.weld.labs.gov.cn

[2] Bo-Qiang Lin, Zhu-Jun Jiang, Environment Kuznets curve prediction and influential factors analysis of China's carbon emission, Management World, 2009(4):27-36

[3] Xiao-Yan Shen, The analysis and prediction of China's carbon emission, Statistic and Decision, 2010(19):90-92

[4] Chang-Kai Wang, Hong-Zuo Xie, Analysis on Dynamic Characteristics and Influencing Factors

of Carbon Emissions from Electricity in China, China Population, Resources And Environment, 2015(4)

[5] Dalia Streimikiere, Kaya identity for analysis of the main drivers of GHG emissions and feasibility to implement EU “20-20-20” targets in the Baltic States, Renewable and Sustainable Energy Reviews, 1108-1113.

[6] Yu-Zhe Wu ,The impact of urbanization on carbon emissions in developing countries: a Chinese study based on the U-Kaya method, Journal of Cleaner Production, 589-603

[7] Georgios Mavromatidis, A strategy for reducing CO2 emissions from buildings with the Kaya identity - A Swiss energy system analysis and a case study, Energy Policy, 343-354

[8] Lin Yao, Quality monitoring method of strip hot-dip galvanizing based on partial least squares regression, Journal of University of Science and Technology Beijing, 28-33 
[9] Hua-Ding Shi, Yong-Qing Qi, The Research of Greenhouse Gas Accounting System for Power Industry, Advances In Climate Change Research, 1673-1719 (2010) 01-0040-07

[10]Zhuo Li, Ning-Zhang, Studied on the accounting method of carbon emissions from power generation industrial, Artical of Science and Technology, 12-13

[11]Shen-Shen Su, Jing-Yang Zhao, Greenhouse Gas Emissions from Power Sector in China from 1990-2050. 